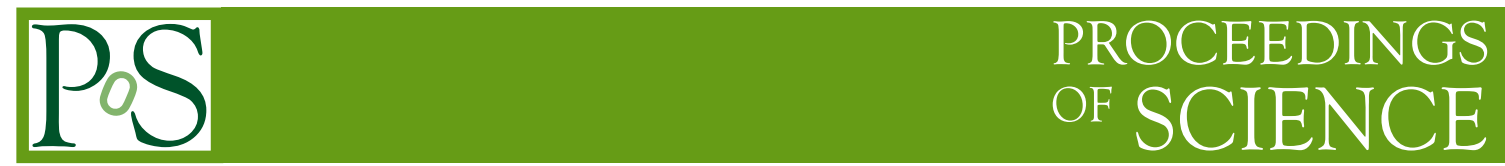

\title{
Review of Dark Matter Direct Searches
}

\author{
Jules Gascon* \\ Institut de Physique Nucleaire de Lyon \\ E-mail: j.gascon@ipnl.in2p3.fr
}

Direct Dark Matter Searches are experiments looking for the energetic recoils due to the scattering of Weakly Interacting Massive Particles (WIMPs) from our galactic halo on nuclei in a terrestrial target. The principles of these type of searches is described, and the status and results of the leading experiments in that field are presented, as well as their prospects in the coming years.

Frontiers of Fundamental Physics 14 - FFP14,

15-18 July 2014

Aix Marseille University (AMU) Saint-Charles Campus, Marseille

${ }^{*}$ Speaker. 